FAMILY CARER PERSPECTIVES OF ACUTE HOSPITAL CARE FOLLOWING A DIAGNOSIS OF MOTOR NEURONE DISEASE: A QUALITATIVE SECONDARY ANALYSIS

Corresponding author: Mary R O'Brien, Evidence-based Practice Research Centre (EPRC), Edge Hill University, Ormskirk, Lancashire, UK. L39 4QP. Email obrienm@edgehill.ac.uk. 01695650918.

Harriet Preston, Locum Consultant in Palliative Medicine, St Catherine's Hospice, Lostock Lane, Lostock Hall, Preston, Lancashire, UK

Running title: Acute hospital care in MND

Keywords: motor neurone disease; carers; qualitative research; acute hospital; secondary analysis

Word count: $\mathbf{3 4 9 0}$ 


\section{FAMILY CARER PERSPECTIVES OF ACUTE HOSPITAL CARE FOLLOWING A DIAGNOSIS OF MOTOR NEURONE DISEASE: A QUALITATIVE SECONDARY ANALYSIS}

\section{Objectives}

The multi-faceted nature of the problems faced by someone with motor neurone disease requires a knowledgeable multidisciplinary team approach. Where available, generally, such services are only provided on an out-patient basis meaning that hospitalised patients are frequently admitted to non-specialist wards where understanding of their needs is limited. Little is known regarding the in-patient care received by patients. Our objective was to address this by exploring the experience of hospitalisation following a diagnosis of motor neurone disease from the perspective of family carers of those diagnosed with the illness.

\section{Method}

This was a qualitative secondary analysis of pre-existing data from two previously published, separately conducted, qualitative studies. The study involved interview data from 18 bereaved carers and 3 current carers of family members diagnosed with motor neurone disease in Northwest England.

\section{Results}

The findings reveal dissatisfaction with the in-patient care received which impacted negatively not only on patient and carer enthusiasm for future hospital admissions but also on carer bereavement.

\section{Conclusion}

Patients with motor neurone disease have specialist needs which are not always met during hospital admission, particularly to non-specialist units. The in-patient care provided for these patients must be improved as must the knowledge and understanding of the illness amongst healthcare professionals who treat them. 


\section{FAMILY CARER PERSPECTIVES OF ACUTE HOSPITAL CARE FOLLOWING A DIAGNOSIS OF MOTOR NEURONE DISEASE: A QUALITATIVE SECONDARY}

\section{ANALYSIS}

\section{INTRODUCTION:}

Motor neurone disease (MND) is a progressive neurological condition with a median survival from symptom onset of 25 months. [1] Upper and lower motor neurone degeneration result in skeletal muscle weakness and wasting with consequent loss of functional ability in associated limbs. Bulbar involvement causes speech and swallowing difficulties and has strong correlation with a reduced vital capacity; [2] some patients will present with respiratory symptoms. The usual cause of death is respiratory failure.

Internationally recognised guidelines for the management of the condition recommend a multidisciplinary approach to care.[3] Additionally, it has long been acknowledged that MND care should encompass a palliative approach, from diagnosis; palliative care guidelines for MND have been developed [4] and the need for specialist palliative care in MND is recognised.[5] In the UK, the National Service Framework (NSF) for Long Term conditions [6] stressed the need for integrated care combining specialist neurology, rehabilitation and palliative care services as part of lifelong care in MND. Furthermore, there is a need for improvements in the care provided for neurological patients in settings such as nonneurological wards. [6]

Within many countries worldwide, specialist MND centres provide on-going multidisciplinary follow-up for patients after diagnosis. European studies suggest improved outcomes, in terms of survival $[7,8]$ and reduced frequency of hospital admissions, [8] amongst patients who attend these specialist MND multidisciplinary centres rather than general neurology clinics. Multidisciplinary team working is known to help MND patients to feel supported.[9] These services are, by and large, provided on an out-patient basis and coverage is not universal with sparse availability in rural locations; figures are not available to accurately determine the 
proportion of MND patients worldwide who have access to specialist multidisciplinary care. It has been identified that only $21 \%$ of Scottish MND patients accessed specialist clinics,[10] though these figures are now dated; at most, specialist MND care centres cover only $60 \%$ of England.[11]

Most people with MND are cared for in their own homes by family members and a majority of them will die in their own homes.[12] However, people with MND can experience a number of hospital admissions throughout their illness. These may be planned for specific interventions, such as feeding tube insertion, or emergency hospitalisation as a result of concomitant illness, worsening condition, or for terminal care.

Research into hospital care at the end-of-life has featured experiences during malignant illness $[13,14]$ and stroke.[15] A literature review concerning MND patients' experiences of, and preferences for, care revealed that dissatisfaction with services abounds [16]. However little attention has been directed towards understanding patient or family carer experiences of inpatient care. This study, therefore, aimed to address this shortfall by exploring the experiences of hospitalisation which occurred after a diagnosis of MND was made, (i.e. not related to the diagnostic process), from the perspective of family carers of people diagnosed with the illness.

\section{METHODS:}

The study reports on a secondary analysis [17] of pre-existing data from two previously published qualitative studies conducted, separately, by the authors in Northwest England, with data collected during 2008-2009. [18,19] Similarities in study design and datasets meant it was possible to combine the data and conduct additional topic-focused analysis. This method has previously been adopted by other researchers to explore attitudes of patients and carers towards peer support in MND [20] and carers' experiences of the death of a family member from MND.[21] As experience of hospitalisation was evident in both data sets, but was not the primary focus of either of the original studies, secondary analysis was an appropriate approach to explore the topic in some depth. 
The strategies used in the original studies are detailed elsewhere. Briefly, they comprised of purposive sampling of family carers of people with MND resident in Northwest England, exploring experiences of accessing health, social and palliative care services [18,22] or experiences using the Preferred Priorities for Care (PPC) document. [19] Similar methodological approaches were adopted in the original studies with data collected using prompts within narrative style interviews. Only interview transcripts that featured experiences of hospitalisation were included in the secondary analysis; the pooled sample therefore consisted of $10 / 10$ bereaved carers from study 1 (see table 1 ) and 10/11 bereaved carers from study 2 (see table 2) together with 3/18 current carers from study 1 (see table 3 ). Although the studies were conducted at different times, two participants took part in both studies and are recognised within the results as having two identification codes; consequently there were, in total, 18 bereaved carers included in this study. It is noteworthy that despite there being over 12 months between the studies, these two participants' perceptions of events were unchanged in their later interview.

\begin{tabular}{|l|l|l|l|}
\hline ID & $\begin{array}{l}\text { Relationship to } \\
\text { deceased }\end{array}$ & Gender & $\begin{array}{l}\text { Time since } \\
\text { bereavement }\end{array}$ \\
\hline $\mathbf{3 0 1}$ & wife & F & 10 months \\
\hline $\mathbf{3 0 2}$ & wife & F & 6 months \\
\hline $\mathbf{3 0 3}$ & husband & M & 1 year \\
\hline $\mathbf{3 0 4}^{\circ}$ & wife & F & 2 months \\
\hline $\mathbf{3 0 5}^{*}$ & husband & M & 2 years \\
\hline $\mathbf{3 0 6}$ & wife & F & 2 years \\
\hline $\mathbf{3 0 7}$ & wife & F & 5 years \\
\hline $\mathbf{3 0 8}$ & husband & M & 5 years \\
\hline $\mathbf{3 0 9}$ & wife & F & 2 years \\
\hline $\mathbf{3 1 0}$ & wife & F & 7 years \\
\hline
\end{tabular}

Table 1. Bereaved carers included from study $1[18 ; 22]$

('ID2 \& ID304 are the same person; *ID7 \&ID 305 are the same person) 


\begin{tabular}{|l|l|l|l|}
\hline ID & $\begin{array}{l}\text { Relationship to } \\
\text { deceased }\end{array}$ & Gender & $\begin{array}{l}\text { Time since } \\
\text { bereavement }\end{array}$ \\
\hline $\mathbf{1}$ & son & M & 9 months \\
\hline $\mathbf{2}^{\mathbf{2}}$ & wife & F & 15 months \\
\hline $\mathbf{3}$ & husband & M & 5 months \\
\hline $\mathbf{5}$ & wife & F & 9 months \\
\hline $\mathbf{6}$ & father and son & M & 15 months \\
\hline $\mathbf{7}^{*}$ & husband & M & 3 years 3 months \\
\hline $\mathbf{8}$ & wife & F & 10 months \\
\hline $\mathbf{9}$ & husband & M & 15 months \\
\hline $\mathbf{1 0}$ & husband & M & 13 months \\
\hline
\end{tabular}

Table 2. Bereaved carers included from study 1 [19]

\begin{tabular}{|l|l|l|l|}
\hline ID & Relationship & Gender & $\begin{array}{l}\text { Disease duration (at } \\
\text { interview) }\end{array}$ \\
\hline $\mathbf{2 1 4}$ & wife & F & 30 months \\
\hline $\mathbf{2 1 5}$ & husband & M & 9 months \\
\hline $\mathbf{2 1 6}$ & husband & M & 8 months \\
\hline
\end{tabular}

Table 3. Current carers included from study 2 [18;22]

\section{Ethics:}

Both studies were originally approved by separate NHS Ethical committees who subsequently extended permission to undertake this secondary analysis.

\section{Analysis:}

The method adopted followed that described in detail by Locock and Brown.[20] We each identified relevant extracts, related to hospital care, from our full transcripts which we exchanged to allow each other to become familiar with the data and begin analysis independently. We were thus able to view the data afresh although, as was the case elsewhere,[20] our interpretation was predictably influenced by familiarity with our own data. We separately identified themes and then met to discuss and debate these initial findings to identify where agreement/disagreement was present. These discussions ultimately led to a consensus regarding the emergent themes, lack of knowledge, basic care, reluctance for admission and final memories which are supported with quotations to ensure the findings are grounded within the data.

\section{RESULTS:}




\section{Lack of knowledge}

This study identified many negative experiences for MND patients during hospital admission. Lack of knowledge of MND amongst hospital staff was mentioned by more than half of the participants and was a cause of frustration and anger amongst carers, which could lead to complaints and conflict with staff.

"The staff need an awful lot more training in how to deal with people suffering MND. They've just, there are so many little incidences which show lack of understanding." (ID215)

There was recognition of kindness amongst the staff, but this could be overshadowed by poor understanding of the needs of people with MND.

“They always seemed to take care of him and I can't (grumble) with caring.... I know they're busy but you feel like they don't, they don't know, a lot of 'em don't know what motor neurone is." (ID5)

In some cases this lack of knowledge led to carers spending long periods of time in hospital with the patient to ensure appropriate care was given. They were also acting as experts educating staff about how to care for the MND patient, which brought with it an element of concern for carers.

'I was up at the hospital seeing to him and I was directing one or two of the nurses, you can understand how I felt about this, because expert I am not, but I was experienced with him where the nurses were not. So I wasn't filled with anything except absolute terror really' (ID304/ID2)

However some respondents did acknowledge the rarity of the disease, pressures on staff and their need for training. Satisfaction with care appeared to be greater for planned admissions, especially to specialist wards.

'So we went on the ENT [ward] [for gastrostomy] and they were great, absolutely great' (ID301)

Admission to a neurology ward was favoured over emergency admissions to a medical assessment unit; it was felt that there should be more specialist beds available. 
“The system doesn't cater for special cases, or it doesn't seem to cater for special cases. If you get to the right ward, yes, that's fine but it's getting to that ward, that's the problem and when you go in, in an ambulance, you automatically go in an assessment ward...I think anybody who has got MND should actually be sent to the... [neurology ward] even if it's to lie on a trolley, at least the nurses there know how to treat them."

(I305/ID7)

Basic care

Significant disability meant that some MND patients were unable to meet their own hygiene needs whilst in hospital. A number of respondents could not understand why their relatives were subjected to a lack of basic care while in hospital.

“It was filthy... he didn't have a wash or a shave, for two days, he couldn't help himself, couldn't do anything for himself until I went at visiting time the day after and gave him a wash and shave, it wasn't how you would want your loved one to be looked after." (ID306)

Respondents not only reported lack of attention to the basics such as washing and feeding, there were also complaints about communication with health care professionals; some were felt to be inflexible with regard to patients' wishes and preferences.

“'No' every answer was 'no' they couldn't do it and I was trying to make sure [patient's] wishes were respected but it was a waste of time really, the hospital staff had their own agenda and that agenda didn't agree with ours so ours went out of the window." (ID6)

\section{Reluctance for admission}

Many patients had lost the ability to speak at the time of hospital admission but there appeared to be little attempt, at times, to enhance their capacity to communicate, with relatives often having to act as patient advocate. Patients were described as feeling frustrated, abandoned and alone. Unsurprisingly some relatives and patients expressed reluctance for admission to hospital.

"they shoved her in a side room in Medical Admissions and nobody bothered with her, you know, because she couldn't communicate and err, because she had a [writing] pad there and everything, but nobody [used the writing pad], 
you know, they just left her and that put her off hospitals altogether, this hospital anyway" (ID10)

This even had the effect of increasing the burden on one carer who was concerned that her husband would be admitted to hospital, which neither he nor she wanted, if she complained that she was experiencing difficulty coping with his needs.

"that was another thing, I kept thinking if I look as if I can't cope they will have him in hospital" (ID306)

\section{Final memories}

Several patients died in hospital and a number of carers revealed the impact of negative experiences during this time on their final memories of their loved one and their subsequent bereavement.

"the last 3 weeks of my mother's life.... and they made it terrible absolutely terrible, well it was horrific....through their incompetence and through their not knowing, the lack of knowledge of motor neurone...I think that's what hurt the most because they, they took the last 15 minutes, 20 minutes of my mother's life from me' (ID1)

"The last few days, they'll haunt me for the rest of my life and the thing that pisses me off is it could have been prevented if people had done their job properly and made an effort" (ID6)

\section{DISCUSSION:}

Health professionals caring for those with MND need to have knowledge and understanding of the illness to ensure that patients receive good standards of specialised care as recommended within published guidelines.[3,6] Poor understanding regarding MND amongst healthcare professionals has previously been recognised;[23] concern has also been expressed about the impact this can have on patient care.[24] Participants in this study felt frustrated when healthcare staff did not provide, what they regarded as, appropriate care due to a lack of understanding of MND. It has been suggested that care could be improved if education and training, specific to MND, was available for health professionals involved in 
treating persons with the illness.[25] However, this is not as straightforward as it might seem; there are many challenges inherent in attempting to increase understanding of what is a relatively low-incidence condition encountered infrequently by many health professionals.[24]

Carer burden in MND is known to be high and increases as the disease progresses with caregiver health suffering as a consequence of extended periods of caring, often exceeding 11 hours a day.[26] It might be presumed that a period of hospitalisation would reduce the demands on carers as health professionals assume responsibility for care provision. However, our participants revealed that unknowledgeable health staff added to their strain as they felt the need to remain at the patient's bedside for long periods of time to ensure that their relative was cared for properly. In addition, as carers had to instruct health professionals regarding aspects of daily care required by their loved ones, their confidence in the ability of the staff to look after their family member was adversely affected. Relatives often felt that they had to act as patient advocate, particularly when their speech was affected, and they felt frustrated when their obvious expertise in caring for their loved one was overlooked, or dismissed altogether, by staff. Although not specific to MND patients, this finding has been previously reported in a study of older people in the acute care setting.[27]

Whilst a lack of basic knowledge of MND amongst health professionals can, to a degree, be expected given the rarity of the condition, what is perhaps more worrying is a perceived lack of basic care provision, care that any patient, regardless of their condition, should expect to receive. Indeed, poor levels of basic care received in hospital, such as washing, dressing and feeding have been increasingly reported, particularly in the wake of the Francis report [28] which identified serious concerns with basic patient care. This was highlighted by the participants in this study. However it is not just physical aspects that are included in "basic care' but also empathy, dignity and respect. Patients experiencing dignified care are more likely to report greater satisfaction with services.[29] Family carers of patients with malignancy consider that the patient's dignity is compromised when there is little regard paid to their 
personal needs.[13] This was also apparent here where carers expressed anger and frustration at the lack of dignity shown to their relatives when their basic needs were unmet.

Dissatisfaction with health care services and a lack of dignified care received by patients with MND has previously been noted.[16] This has resonance with the claims elsewhere $[14,30]$ that concede problems with healthcare often concern situations where the individual feels disempowered, dehumanised and devalued resulting in a threat to their personal identity. Healthcare professionals are viewed increasingly as giving care which is more task-orientated and target-driven than person-centred [31] whereas satisfaction with care appears to be related to more interpersonal aspects. [27] Indeed, nursing kindness was identified as the second most important determinant of global patient satisfaction amongst hospital inpatients.[32]

Respect for the person is hugely important for those with MND [33] as there is concern they will not be treated as a person and their views will not be taken into account. Our findings show that respect for the person was not always evident. Participants reported poor communication between staff and the patient/family led to dissatisfaction with the care provided, particularly when patients' wishes were not respected. This has occurred in spite of the need to value patient autonomy within a therapeutic relationship recognised within guidelines for MND care.[3] The characteristics of effective inclusive practice are those which define the experience as a shared, mutually respectful, positive and empowering one for both practitioner and service user.[34] Findings from this study indicate that the views of MND patients and their carers were not always respected, neither were they regarded as equal partners in decision-making regarding hospital treatment which has implications for the quality of care received. There is clearly a need for education for health professionals so they are more aware of the importance of inclusive practice and the benefits it can bring to patient care.[34]

There is growing recognition of the importance of user satisfaction with health care services as an outcome measure and ward-based patient satisfaction surveys, such as the National 
Health Service (NHS) 'friends and family' test, [35] are increasingly being utilised. Introduced into hospitals in April 2013, the friends and family test is regarded as a way of improving services by giving patients an opportunity to provide feedback on care and treatment received. On discharge patients are asked 'How likely are you to recommend our ward/A\&E department to friends and family if they needed similar care or treatment?' Data are available to the public via NHS Choices and may also be published by individual hospitals themselves [35].

However, research into the concept of patient satisfaction has highlighted that it is highly complex and subjective and therefore unlikely to be captured by a simple 'bedside' survey.[16] Satisfaction can also be influenced by prior episodes of health care; a previous negative experience of hospital admission has been identified as a predictor of reluctance for readmission amongst stroke patients.[36] The results of previous studies of older patients' experiences of acute care have identified that those with communication difficulties are more likely to have a negative experience of care;[27] findings which were re-iterated here. It is therefore not surprising that, in this study, those participants who had reported a poor experience of hospitalisation expressed reluctance for further admission.

Although a significant proportion of the admissions described by participants in this study were elective, e.g., for placement of a feeding tube, and therefore to a specialist ward, it is worth bearing in mind that many MND patients experience unplanned admissions. These are usually as a result of a 'crisis' and consequently relatives are highly likely to be exhausted, both physically and emotionally.[30] Patients experiencing unplanned admissions were far less likely to be cared for on specialist wards where their needs are most likely to be understood, another factor influencing the reluctance for admission amongst some. This has resonance with previous work reporting that carers did not trust generic services and felt more confident when they had access to specialist nurses, or specialist teams.[37]

Unfortunately, for some MND patients such unplanned admissions are for end-of-life care, consequently a negative experience of hospitalisation could adversely affect bereavement. Models of good end-of-life care encompass not just the time around death but the period 
afterwards, incorporating bereavement support. The death of a loved one leaves a lasting legacy for the family and substandard end-of-life care can lead to anger, blame and guilt amongst bereaved relatives.[30] A majority of the public report being frightened of dying in hospital and when asked, most people state a wish to die at home although the reality is that more than half die in hospital.[38] However, evidence suggests that the needs of those dying in hospital may not always be met $[13,39]$ particularly on busy acute wards. Due to the progressive, incurable nature of MND many relatives in this study had previously discussed wishes and preferences regarding end-of-life care, and many of their loved ones had indicated their preferred place of death to be home. Guilt can be felt by relatives if their loved one dies in a place not of their choosing.[22] Indeed, some of the patients referred to in this study died in hospital following crisis admissions, and several participants commented on how a poor experience of hospitalisation, where there was disregard for their views, had adversely affected their bereavement. This has resonance with the assertion that expressions of dissatisfaction with care tend to be related to situations where the individual perceives a threat to their personal identity.[30]

\section{CONCLUSION AND IMPLICATIONS:}

There were minimal comments regarding positive experiences during hospital admissions; MND patients cared for by the participants in this study had specialist needs which were not always met particularly in non-specialist units. This study highlights that, wherever possible, these patients should be cared for on hospital wards where staff have an understanding of their condition and can provide specialised care appropriate to their needs. It also indicates a need for further training and enhanced awareness of MND amongst healthcare professionals, generally. However, although a lack of knowledge specific to MND was evident amongst the staff, some participants appeared more concerned about the lack of basic care experienced by some patients. Both lack of knowledge regarding MND and lack of basic nursing care contributed to a poor experience of hospitalisation for some patients cared for by the 
participants of this study, and this must be addressed. Not only will this improve care received by the patient at a very difficult time but it will also have a lasting legacy for the bereaved.

\section{LIMITATIONS OF THE STUDY:}

This study is subject to the usual limitations inherent in the use of secondary data, in that the data were not specifically collected to answer the research question [40] and as such did not allow for probing to clarify any issues arising. Additionally, both primary studies were conducted in the same geographical area which imposes limits on the transferability of the findings. As the majority of participants included within this study were bereaved carers their accounts are necessarily retrospective; further research exploring hospitalisation experiences, as they occur, from the patients' and health professionals' perspectives would add immensely to our understanding of the topic.

\section{FUNDING}

This secondary analysis received no funding. Some of the data presented in this article are based on independent research funded by the National Institute for Health Research (NIHR) under its Research for Patient Benefit (RfPB) Programme (Grant Reference Number PB-PG0706-10369) (study 1). The views expressed are those of the author(s) and not necessarily those of the NHS, the NIHR or the Department of Health.

The Corresponding Author has the right to grant on behalf of all authors and does grant on behalf of all authors, an exclusive licence (or non exclusive for government employees) on a worldwide basis to the BMJ Publishing Group Ltd to permit this article (if accepted) to be published in BMJ Supportive and Palliative Care and any other BMJPGL products and sublicences such use and exploit all subsidiary rights, as set out in our licence (http://group.bmi.com/products/journals/instructions-for-authors/licence-forms).

Competing Interest: None declared.

\section{ACKNOWLEDGEMENTS}

The authors wish to acknowledge the contribution of the study participants. 


\section{CONTRIBUTORSHIP}

MOB conceived the idea; MOB and HP gathered the data for the original studies and both analysed and interpreted the work presented here.

Both authors were involved in preparing and revising the content and have approved the final version submitted. Both authors agree to be accountable for all aspects of the work. 


\section{REFERENCES:}

1. Forbes RB, Colville S, Cran GW, \& Swingler RJ. Unexpected decline in survival from amyotrophic lateral sclerosis/motor neurone disease. J Neurol Neurosurg Psychiatry 2004;75:1753-1755 doi:10.1136/jnnp.2003.024364

2. Davis M, \& Lou JS. Management of amyotrophic lateral sclerosis (ALS) by the family nurse practitioner: A timeline for anticipated referrals. J Am Assoc Nurse Pract.

$2011 ; 23: 464-472$

3. Miller RG, Rosenberg JA, Gelinas DF. et al. Practice Parameter update: The care of the patient with amyotrophic lateral sclerosis: Multidisciplinary care, symptom management, and cognitive/behavioral impairment (an evidence-based review). Neurology 2009;73;15:12271233

4. Oliver D, \& Webb S. The involvement of specialist palliative care in the care of people with motor neurone disease. Palliat Med;2000;14:427-8.

5. McCluskey L. Palliative rehabilitation and Amyotrophic Lateral Sclerosis: a perfect match. NeuroRehabilitation 2007;22(6):407-408.

6. Department of Health The National Service Framework for Long Term Conditions. London: The Stationery Office, 2005

7. Traynor BJ, Alexander M, Corr B, et al. Effect of a multidisciplinary amyotrophic lateral sclerosis (ALS) clinic on ALS survival: a population based study, 1996-2000. J Neurol Neurosurg Psychiatry. 2003;74:1258-61. doi: 10.1136/jnnp.74.9.1258

8. Chio A, Bottachi E, Buffa C et al. PARALS. Positive effects of tertiary centres for amyotrophic lateral sclerosis on outcome and use of hospital facilities. J Neurol Neurosurg Psychiatry. 2006; 77(8): 948-50 doi: 10.1136/jnnp.2005.083402

9. O'Brien, MR, Whitehead B, Jack BA, et al. Multidisciplinary Team Working in Motor Neurone Disease: The Views of Patients and Family Carers. Br J Neurosci Nurs. 2011;7;4: $580-585$

10. Van Teijlingen ER, Friend E and Kamal AD. Service use and needs of people with motor neurone disease and their carers in Scotland. Health Soc Care Community 2001; 9:397403.

11. All Party Parliamentary Group. Inquiry into Access to Specialist Palliative Care for People with Motor Neurone Disease in England. 2011. http://www.mndassociation.org/getinvolved/campaigning-influencing/all-party-parliamentary-group-inquiry-into-palliative-care [accessed 05/11/2013]

12. Neudert C, OliverD, Wasner M. et al. The course of the terminal phase in patients with amyotrophic lateral sclerosis. J Neurol 2001; 248,7:612-616

13. Spichiger E. Living with terminal illness: patient and carer experiences of hospital end-oflife care. Int J Palliat Nurs, 2008;14; 5: 220-228 
14. Rogers A. \& Karlsen F. All the services were excellent. It is when the human element comes in that things go wrong': dissatisfaction with hospital care in the last year of life. J Adv Nurs, 2000; 31(4): 768-774

15. Young AJ, Rogers A, Dent L. et al. Experiences of hospital care reported by bereaved relatives of patients after a stroke: a retrospective survey using the VOICES questionnaire. 2009; J Adv Nurs, 65, (10), 2161-2174. DOI: 10.1111/j.1365-2648.2009.05081.x

16. Foley J, Timonen $\mathrm{V}$, \& Hardiman O. Patients' perceptions of services and preferences for care in amyotrophic lateral sclerosis: A Review. Amyotroph Lateral Scler, 2012; 13: 11-24. doi: 10.3109/17482968.2011.607500

17. Heaton, J. Reworking qualitative data. London: Sage.2004

18. O'Brien MR, Whitehead B, Jack BA. et al. From symptom onset to a diagnosis of amyotrophic lateral sclerosis/motor neuron disease (ALS/MND): Experiences of people with ALS/MND and family carers - a qualitative study. Amyotroph Lateral Scler, 2011;12: 97104. doi: $10.3109 / 17482968.2010 .546414$

19. Preston H, Cohen Fineberg I, Callagher P. et al. The Preferred Priorities for Care document in Motor Neurone Disease: Views of bereaved relatives and carers. Palliat Med, 2012; vol. 26 no. 2:132-138. doi: 10.1177/0269216311399664

20. Locock L \& Brown J. 'All in the same boat'? Patient and carer attitudes to peer support and social comparison in Motor Neurone Disease (MND). Soc Sci Med 2010;71: 1498-1505. doi: 10.1016/j.socscimed.2010.06.043

21. Ray RA, Brown J, \& Street AF. Dying with motor neurone disease, what can we learn from family caregivers? Health Expect. 2012; Apr 19. doi: 10.1111/j.1369-7625.2012.00773.x

22. Whitehead B, O'Brien MR, Jack BA, et al. Experiences of dying, death and bereavement in motor neurone disease: a qualitative study. Palliat Med, 2012; 26(4):368-78 doi:

$10.1177 / 0269216311410900$

23. Hugel H, Grundy N, Rigby S, et al. How does current care practice influence the experience of a new diagnosis of motor neuron disease? A qualitative study of current guidelines-based practice. Amyotroph Lateral Scler.2006; 7, 161-166

24. Hughes RA, Sinha A, Higginson I, et al. Living with motor neurone disease: lives, experiences of services and suggestions for change. Health Soc Care Community 2005; 13 (1): $64-74$

25. $\mathrm{Ng} \mathrm{L}$, \& Khan F. Multidisciplinary care for adults with amyotrophic lateral sclerosis or motor neuron disease. Cochrane Database Syst Rev. 2009; 7:(4):CD007425. doi: 10.1002/14651858.CD007425.pub2.

26. Krivickas LS, Shockley L, \& Mitsumoto H. Home care of patients with amyotrophic lateral sclerosis (ALS). J Neurol Sci. 1997; Oct;152 Suppl 1:S82-9. 
27. Bridges J, Flatley M, Meyer J. Older people's and relatives' experiences in acute care settings: Systematic review and synthesis of qualitative studies. Int J Nurs Stud.2010; 47:89107

28. Francis, R. Report of the Mid Staffordshire NHS Foundation Trust Public Inquiry. London: The Stationery Office.2013

29. Tadd W, Hillman A, Calnan S. et al. et al Right place - wrong person: dignity in the acute care of older people. Quality in Ageing and Older Adults, 2011;12(1):33-43. Doi: 10.5042/qiaoa.2011.0143

30. Coyle J. Exploring the meaning of 'dissatisfaction' with health care: the importance of 'personal identity threat' Sociol Health IIIn, 1999; 21(1):95-124

31. Jurgens $F$, Clissett $P$, Gladman J. et al.Why are family carers of people with dementia dissatisfied with general hospital care? A qualitative study. BMC Geriatr.2002;12:57. doi: 10.1186/1471-2318-12-57

32. Schoenfelder T, Klewer J, Kugler J. Determinants of patient satisfaction: a study among 39 hospitals in an in-patient setting in Germany. Int J Qual Health Care 2011; 23(5):503-509 doi: 10.1093/intqho/mzr038.

33. Bolmsjo, I.Existential issues in palliative care: interview of patients with amyotrophic lateral sclerosis. Journal of Palliative Medicine. 2001; 4:499-505.

34. Cook T, Atkin H, Carter L. et al. Towards Inclusive Living: A Case Study of the Impact of Inclusive Practice in Neuro-Rehabilitation/Neuro-Psychiatry Services. 2012. http://www.Itnc.org.uk/download files/final\%20reports/April\%2012/2012/2012/Inclusive\%20p ractice final\%20report.pdf [accessed 05/11/2013]

35. NHS England Friends and Family test. http://www.england.nhs.uk/2013/07/30/nhsfft/ friends and family test

36. Mackintosh JE, Murtagh MJ, Rodgers H. et al. Why People Do, or Do Not, Immediately Contact Emergency Medical Services following the Onset of Acute Stroke: Qualitative Interview Study. PLoS One. 2012; 7(10): e46124. Published online 2012 October 4. doi: 10.1371/journal.pone.0046124

37. Jackson D, Williams D, Turner-Stokes $L$. et al. How do carers of people with long term neurological conditions experience the provision of replacement care? Final report to the Department of Health R\&D grant 053/0012. 2011.

http://www.csi.kcl.ac.uk/files/Executive\%20summary\%20-

\%20Replacement\%20care\%20for\%20LTNC\%20carers\%20May\%202011.pdf [accessed 05/11/2013]

38. National End-of-life Care Intelligence Network. What do we know now that we didn't know a year ago? New intelligence on end-of-life care in England. Department of Health. 2012. http://www.endoflifecareintelligence.org.uk/resources/publications/what we know now [accessed 05/11/2013]

39. Donnelly S, \& Battley J. Relatives' experience of the moment of death in a tertiary referral hospital. Mortality, 2010;15(1):81-100. DOI:10.1080/13576270903537641 
40. Boslaugh S. (2007) Secondary Data Sources for Public Health: A Practical Guide. New York: Cambridge University Press 2007978-0-521-87001-6 